\title{
The origin of the effects of an anticholinesterase on the latencies of action potentials in mouse skeletal muscles
}

\author{
'S.S. Kelly \& C.B. Ferry
}

Pharmacological Laboratories, Pharmaceutical Sciences Institute, Aston University, Birmingham B4 7ET

1 Subcutaneous injection in mice of a single dose of an organophosphorous anticholinesterase, ecothiopate $\left(0.5 \mu \mathrm{mol} \mathrm{kg}^{-1}\right)$, produced increased variability in the latency (jitter) of indirectly-elicited action potentials in diaphragm muscles 5 days after treatment, but there was no effect on the variability of latencies of endplate potentials. This study was designed to elucidate the mechanism(s) of the increase in action potential jitter.

2 Action potentials evoked directly by electrical stimulation at one end of muscle fibres and recording near the other end had less jitter than indirectly-evoked action potentials and ecothiopate had no effect on directly-evoked action potentials.

3 In preparations with uncut fibres, pretreatment with ecothiopate reduced by about $20 \%$ both muscle fibre input resistance and the amplitude of spontaneous miniature endplate potentials. Ecothiopate had no effect on muscle fibre resting membrane potential or on the threshold potential for excitation.

4 In untreated preparations, indirectly-evoked action potentials recorded at the endplate had similar jitter to action potentials recorded at the tendon when latencies were measured at $10 \%$ of peak amplitude. However, when latencies were measured at peak, there was greater jitter of action potentials at the endplate. Ecothiopate increased jitter of action potentials recorded at the endplate at $10 \%$ of peak but did not significantly increase jitter of action potentials recorded at the endplate when measured at the peak.

5 In cut-fibre preparations, the first endplate potential of trains was significantly increased after ecothiopate but there was no effect of ecothiopate on the amplitude of plateau endplate potentials later in the train. Analysis of plateau endplate potentials showed that 5 days after administration, ecothiopate produced an increase in the variance of endplate potential amplitudes and changes in the binomial parameters $\mathrm{n}$ and $\mathrm{p}$.

6 It was concluded that the increased jitter produced by ecothiopate is not a generalized effect on the plasma membrane and that none of the above observations could explain the increased jitter. The possibility is discussed that increased jitter is produced by variability in times to threshold of endplate potentials and/or by variability in the locus of generation of the action potential in the perijunctional area.

Keywords: Organophosphorous anticholinesterases; action potentials; quantum content; mouse skeletal muscle

\section{Introduction}

Experiments reported by Kelly et al. (1990) showed that the 'jitter' i.e. the variability of latencies of indirectly-elicited diaphragm muscle action potentials was increased 5 days after administration of a single dose $\left(0.5 \mu \mathrm{mol} \mathrm{kg}^{-1}\right)$ of ecothiopate, a quaternary organophosphate. Two other anticholinesterase organophosphates also increased jitter, and this effect appeared to be related to the degree and duration of the initial inhibition of acetylcholinesterase, although the increased jitter lasted for several days after acetylcholinesterase activity had returned to control values. Furthermore, later studies (Kelly et al., 1992) also showed that the increased jitter could be reduced or prevented by protection or early reactivation of acetylcholinesterase. This indicates that prolonged inhibition of acetylcholinesterase is at least the initiator of the increased jitter.

In untreated preparations, jitter of endplate potentials and action potential jitter were not different from each other. After ecothiopate, the increased jitter of the action potentials recorded at the tendon end of the muscle fibres was not accompanied by a change in endplate potential jitter. It was concluded that normal jitter in untreated mice was possibly

\footnotetext{
1 Author for correspondence at present address: Department of Environmental and Occupational Medicine, The Medical School, University of Newcastle upon Tyne, NE2 4HH.
}

presynaptic in origin, or at least influenced by the endplate potential jitter. However, the increased jitter after ecothiopate was not caused by altered timing of transmitter release but may have originated after the production of the endplate potential and before the arrival of the action potential at the tendon end of the fibre. Increased jitter of muscle action potentials may be produced during generation of the action potentials and/or during their conduction along the muscle fibre. The purpose of this study was to elucidate the origin of the increased jitter produced by ecothiopate.

In order to determine if altered conduction of the action potential along the muscle fibre might contribute to the increased jitter after ecothiopate, action potentials were produced by direct electrical stimulation of the muscle fibre, thus bypassing the process of neuromuscular transmission. In other experiments, indirectly-evoked action potentials were recorded at the endplate region of muscle fibres to determine whether the jitter of these action potentials after ecothiopate was increased similarly to jitter of action potentials near the tendon or was unchanged as with endplate potentials. Evoked endplate potentials were studied in cut-fibre preparations so that any prejunctional changes produced by ecothiopate might be identified. A further investigation was made of the effect of ecothiopate on the safety factor of neuromuscular transmission which might produce an increased jitter by affecting the generation of the action potential in the endplate region. 


\section{Methods}

The anticholinesterase used was ecothiopate (S-(2-trimethylammoniumethyl)phosphorothioate iodide). Ecothiopate was made up from Phospholine Eyedrops powder (Ayerst). This powder consisted of $12.5 \mathrm{mg}$ ecothiopate and $40 \mathrm{mg}$ potassium acetate, but when dissolved and diluted the amount of potassium injected was negligible (approximately $6.0 \mu \mathrm{mol}$ $\mathrm{kg}^{-1}$ ).

Male albino mice aged 6-7 months were used in all experiments. At various times after subcutaneous injection of ecothiopate iodide $\left(0.5 \mu \mathrm{mol} \mathrm{kg}^{-1}\right)$ with atropine $(0.7 \mu \mathrm{mol}$ $\mathrm{kg}^{-1}$ ), animals were killed by decapitation. The inclusion of atropine in the injection prevents muscarinic effects caused by inhibition of acetylcholinesterase. The acute toxic effect of a subcutaneous injection of a mixture of atropine sulphate and ecothiopate was fasciculation, which usually began about $20 \mathrm{~min}$ after the injection and lasted up to $2 \mathrm{~h}$. During this period animals were able to move around, but usually remained quiet with reduced exploratory behaviour. Dosing was in the morning so that the reduced mobility did not coincide with the normal feeding/activity pattern. None of the many human studies refer to any association of pain with fasciculation after organophosphate poisoning (Heath \& Vale, 1992; Johnson \& Vale, 1992).

The left hemidiaphragm, together with its phrenic nerve, was rapidly removed from each animal and pinned to Sylgard 184 (Dow Corning) in a Perspex bath through which flowed physiological saline of the following composition (mM): $\mathrm{NaCl} 137, \mathrm{NaHCO}_{3} 12, \mathrm{NaH}_{2} \mathrm{PO}_{4} 1, \mathrm{KCl} 5, \mathrm{CaCl}_{2} 2$, $\mathrm{MgCl}_{2} 1$ and glucose 25 . The saline was gassed with a mixture of $95 \% \mathrm{O}_{2}$ and $5 \% \mathrm{CO}_{2}$ and the temperature was maintained at $37.0 \pm 0.5^{\circ} \mathrm{C}$. The phrenic nerve was stimulated via a suction electrode with supramaximal pulses of $0.05 \mathrm{~ms}$ duration. For direct stimulation of the muscle, two silver wires about $0.5 \mathrm{~mm}$ apart and embedded in Araldite with only the tips exposed, were used to deliver pulses of duration of $0.2 \mathrm{~ms}$ and amplitude twice threshold. For both direct and indirect stimulation the stimulus frequency was $30 \mathrm{~Hz}$.

Glass capillary microelectrodes filled with $3 \mathrm{M} \mathrm{KCl}$ were used to record intracellularly resting membrane potentials, action potentials, endplate potentials and spontaneous miniature endplate potentials. When recording action potentials, many pins were used to fix the muscle to the Sylgard and, if necessary, some muscle fibres were cut to minimize muscle movement in response to nerve stimulation. In order to record endplate potentials and to prevent the muscle twitching in response to nerve stimulation, the muscle fibres were cut (Barstad, 1962; Hubbard \& Wilson, 1973).

\section{Recording of action potentials}

When elicited by nerve stimulation, action potentials were recorded either focally at the endplate or at the end of uncut muscle fibres near the tendon. However, when action potentials were elicited by direct stimulation close to the central tendon of the muscle, recordings were made either close to the costal tendon or close to the endplate region but on the rib side of the endplate. Recordings were made from these two sites in order to detect any incremental changes which might take place during conduction, although at both sites the action potential was conducted through the endplate region. Action potentials were displayed on an oscilloscope and recorded on an FM tape recorder (Racal Store 4) with a tape speed of 30 inches per second (i.p.s.). These recordings were then replayed at $15 / 16$ i.p.s. and were analysed with an analogue-to-digital (AD) converter and a PDP 11/03 minicomputer. With an AD sampling rate of $20 \mathrm{kHz}$ and a record/replay ratio of 32 , the effective sampling rate of the recordings was $640 \mathrm{kHz}$. Trains of 30 action potentials were recorded from each muscle fibre and approximately 10 fibres were sampled from each muscle. Data from a fibre were rejected if, during the train, the resting membrane potential fell by more than $5 \mathrm{mV}$ or the action potential amplitude fell by more than $10 \%$.

\section{Recording of miniature endplate potentials and endplate potentials}

Miniature endplate potentials and endplate potentials were recorded on an FM tape recorder and on replay were displayed on an oscilloscope and were analysed on-line using an analogue-to-digital converter and a PDP 11/03 minicomputer. The recording of miniature endplate potentials with a rise-time to amplitude ratio of less than $1.1 \mathrm{~ms} / \mathrm{mV}$ was the criterion for the focal location of the microelectrode at the endplate. Between 50 and 200 miniature endplate potentials were recorded from each muscle fibre and approximately 10 fibres were sampled from each muscle. The amplitude of spontaneous and evoked endplate potentials was corrected for non-linear summation and to a standard resting membrane potential. In intact fibres the standard resting membrane potential for correction was $-70 \mathrm{mV}$ assuming the reversal potential to be $-15 \mathrm{mV}$, and in cut fibres the standard resting membrane potential was $-50 \mathrm{mV}$. The mean amplitude and frequency of miniature endplate potentials were calculated at each end-plate. Martin's correction for non-linear summation (Martin, 1955) was empirically trimmed by a factor of 0.7 in cut fibres so that corrected endplate potential amplitudes would not exceed the reversal potential of $-5 \mathrm{mV}$ in these preparations (McLachlan \& Martin, 1981).

\section{Analysis of evoked potentials}

Computer programmes were devised which measured the amplitude, time course, and latency of each evoked potential, the latency being the interval between the stimulus and a point on the rising phase at $10 \%$ of peak amplitude. Those data were used to calculate (i) the mean consecutive difference of latencies of action potentials 11-30 (plateau) and (ii) individual latencies of the first 16 action potentials with respect to the first action potential of the train. The formula used to calculated the mean consecutive difference was:

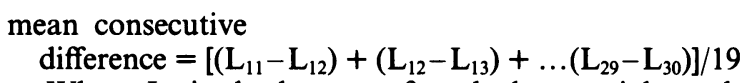

Where $L_{n}$ is the latency of evoked potential number $n$.

Using the mean consecutive difference as a measure of variability is thought to reduce the effects of any long-term drifts in latency, but might hide any initial changes at the beginning of trains of action potentials (Ekstedt et al., 1974). In our experiments, the initial change is measured as the 'delay' of the sixteenth action potential relative to the first action potential (i.e. latency of sixteenth action potential minus latency of first action potential). Using a pulse generator accurate to 1 in $10^{6}$ (Digitimer) to simulate action potentials at $10 \mathrm{~Hz}$, the value obtained for mean consecutive difference was $2.4 \mu \mathrm{s}$, which represents the intrinsic error of the process of record/replay/analysis.

\section{Analysis of miniature endplate potentials and endplate potentials}

A train of 50 endplate potentials was recorded from each muscle fibre and the mean amplitude of the last 40 (plateau) endplate potentials was calculated. The mean quantum content of the endplate potentials in each muscle fibre was determined directly by dividing the mean corrected endplate potential amplitude by the mean corrected miniature endplate potential amplitude. The binomial parameters $n$ and $p$ were calculated from amplitudes of miniature endplate potentials and endplate potentials at the plateau (Miyamoto, 1975; McLachlan, 1978). Values were accepted only from data which conformed to binomial statistics. For this reason, the observed and calculated distributions of endplate potential 
amplitudes were compared by the Chi-squared test. The equations used to calculate the endplate potential amplitudes expected if the distribution were binomial (Miyamoto, 1975) were incorporated into a computer programme, the validation of which has been described elsewhere (Kelly \& Robbins, 1987).

\section{Measurement of input resistance and threshold}

Two electrodes were put into the same fibre within $50 \mu \mathrm{m}$ of each other at the endplate region, detected by the presence of focal miniature endplate potentials, and a hyperpolarizing current of $10^{-8} \mathrm{~A}$ was injected through one electrode. The voltage change was recorded through the other electrode, enabling the input resistance to be calculated. To determine the threshold for excitation, a depolarizing current of $5 \mathrm{~ms}$ duration was passed and the resting potential and response to depolarization were recorded on a digital storage oscilloscope. The voltage at which the action potential was initiated was taken as the threshold of that fibre.

\section{Statistical analysis}

Unless otherwise stated, all results are expressed as mean \pm 1 s.d. of values from two to five animals, with the number of muscle fibres in parentheses. To test for significance of differences between groups of data, non-parametric tests were used and differences were taken to be significant if $P<0.05$ (2-tail). For data on jitter, i.e. delay and mean consecutive difference, usually the Kolmogorov-Smirnov test was used as this is more sensitive to changes in the skewnness of the distributions under test. Because reciprocal transformation of mean consecutive difference values normalizes its distribution (Baker et al., 1987), the Mann-Whitney test was also applied to groups of mean consecutive difference data thus transformed. Groups of other data were compared by the MannWhitney test.

\section{Results}

\section{Characteristics of action potentials produced by direct stimulation}

The characteristics of directly-evoked action potentials, recorded either close to the costal tendon or more centrally, i.e. closer to the endplate, are shown in Table 1. Treatment with ecothiopate had no effect on the mean consecutive difference or on the delay. The latency of action potentials elicited by direct stimulation usually decreased throughout the early part of the train. This decreased latency may be artefactual, perhaps due to movement of muscle relative to the stimulating electrodes during the contraction, or it may be due to some use-dependent biological phenomenon. With direct stimulation the action potentials recorded near the tendon had a mean consecutive difference significantly less than that recorded after nerve stimulation, irrespective of whether or not the mice had been treated with ecothiopate (see also Table 3 and data of Kelly et al., 1990, their Table 2).

\section{Effect of ecothiopate at the endplate of intact fibres}

Five days after treatment with ecothiopate there was a decrease in the amplitude and frequency of miniature endplate potentials and also a decrease in the input resistance of the muscle fibres (Table 2). At this time there was no effect of ecothiopate on the half-decay time of miniature endplate potentials, on resting membrane potential or on the threshold depolarization required to initiate a muscle action potential. The mean amplitude of miniature endplate potentials in ecothiopate-treated fibres was $83 \%$ of the value in untreated fibres, and the input resistance at the endplate was similarly decreased to $80 \%$ of that of untreated diaphragms. As the resting membrane potential was unaltered and if it were assumed that the reversal potential of the miniature endplate potentials was also unchanged, these results suggest that the reduction in miniature endplate potential amplitude after ecothiopate was due to the smaller input resistance.

\section{Indirectly-evoked action potentials at the endplate}

Measuring latencies at $10 \%$ of peak amplitude, jitter of endplate potentials and of action potentials recorded at the endplate both measure the variability of latencies of the endplate potential but at different levels. Jitter of action potentials recorded at the endplate at a trigger of $10 \%$ would still represent the jitter of the endplate potential, but at a more depolarized trigger level than the usual endplate potential measurements. To measure the jitter of the action potentials at the endplate, the trigger level must be higher than $10 \%$. Records of action potentials at the endplate were analysed twice at two different trigger levels. One was the usual $10 \%$ of peak amplitude, the other trigger level was the peak itself; the results are shown in Table 3. In untreated

Table 1 Characteristics of action potentials produced by direct stimulation of the muscle close to the central tendon

\section{Untreated}

A Tendon
Resting membrane
potential $(\mathrm{mV})$
Amplitude $(\mathrm{mv})$
Time to peak $(\mu \mathrm{s})$
Mean consecutive
difference $(\mu \mathrm{s})$
Delay $(\mu)$
B Central
Resting membrane
potential $(\mathrm{mV})$
Amplitude $(\mathrm{mV})$
Time to peak $(\mu \mathrm{s})$
Mean consecutive
difference $(\mu \mathrm{s})$
Delay $(\mu \mathrm{s})$

$$
\begin{gathered}
-72 \pm 6(27) \\
81 \pm 9(27) \\
219 \pm 32(27) \\
5.6 \pm 3.8(27)^{*} \\
-57 \pm 50(27)^{*} \\
-73 \pm 5(18) \\
79 \pm 6(18) \\
226 \pm 12(18) \\
3.8 \pm 1.9(18) \\
-40 \pm 42(18)
\end{gathered}
$$

\section{Ecothiopate}

$$
\begin{gathered}
-73 \pm 5(28) \\
81 \pm 7(28) \\
213 \pm 32(28) \\
4.2 \pm 1.3(28)^{*} \\
-70 \pm 51(28)^{*} \\
-71 \pm 4(27) \\
79 \pm 8(27) \\
231 \pm 36(27) \\
4.5 \pm 2.0(27) \\
-24 \pm 71(27)
\end{gathered}
$$

Stimuli of $0.2 \mathrm{~ms}$ duration were twice threshold amplitude; action potentials were recorded either close to the ribs (tendon) or close to the endplate between the endplate and the ribs (central). Values are mean $\pm 1 \mathrm{~s} . \mathrm{d}$., with the number of muscle fibres in parentheses. Ecothiopate $\left(0.5 \mu \mathrm{mol} \mathrm{kg}{ }^{-1}\right)$ given 5 days before recording had no effect. There was no difference between values in untreated animals and values after ecothiopate. Asterisk indicates value is significantly different from that found with indirect stimulation (see Table 3 and Kelly et al., 1990). 
Table 2 Electrophysiological parameters at the endplate in intact muscle fibres 5 days after treatment with ecothiopate $\left.(0.5 \mu \mathrm{mol} \mathrm{kg})^{-1}\right)$

Parameter
Resting membrane
potential $(\mathrm{mV})$
Miniature endplate
potential amplitude $(\mathrm{mV})$
Miniature endplate
potential half-decay $(\mathrm{ms})$
Miniature endplate
potential frequency $(\mathrm{Hz})$
Input resistance $(\mathrm{kohm})$
Threshold $(\mathrm{mV})$

$\begin{array}{cc}\text { Untreated } & \text { Ecothiopate } \\ -71 \pm 3(48) & -71 \pm 3(30) \\ 0.93 \pm 0.23(48) & 0.77 \pm 0.18(30)^{*} \\ 1.5 \pm 0.3(48) & 1.8 \pm 0.5(30) \\ 4.9 \pm 2.4(48) & 2.6 \pm 1.3(30)^{*} \\ 627 \pm 151(31) & 502 \pm 145(26)^{*} \\ 14.8 \pm 2.5(15) & 14.0 \pm 1.9(14)\end{array}$

Values are mean \pm 1 s.d., with the number of muscle fibres sampled in parentheses. Asterisk indicates significant difference between value after ecothiopate and value in untreated animals.

Table 3 (A) The delay of action potential 16 with respect to the first action potential and (B) mean consecutive difference of endplate potentials or action potentials recorded at the endplate or at the tendon with measurement point for analysis of latencies set at $10 \%$ of action potential or at its peak

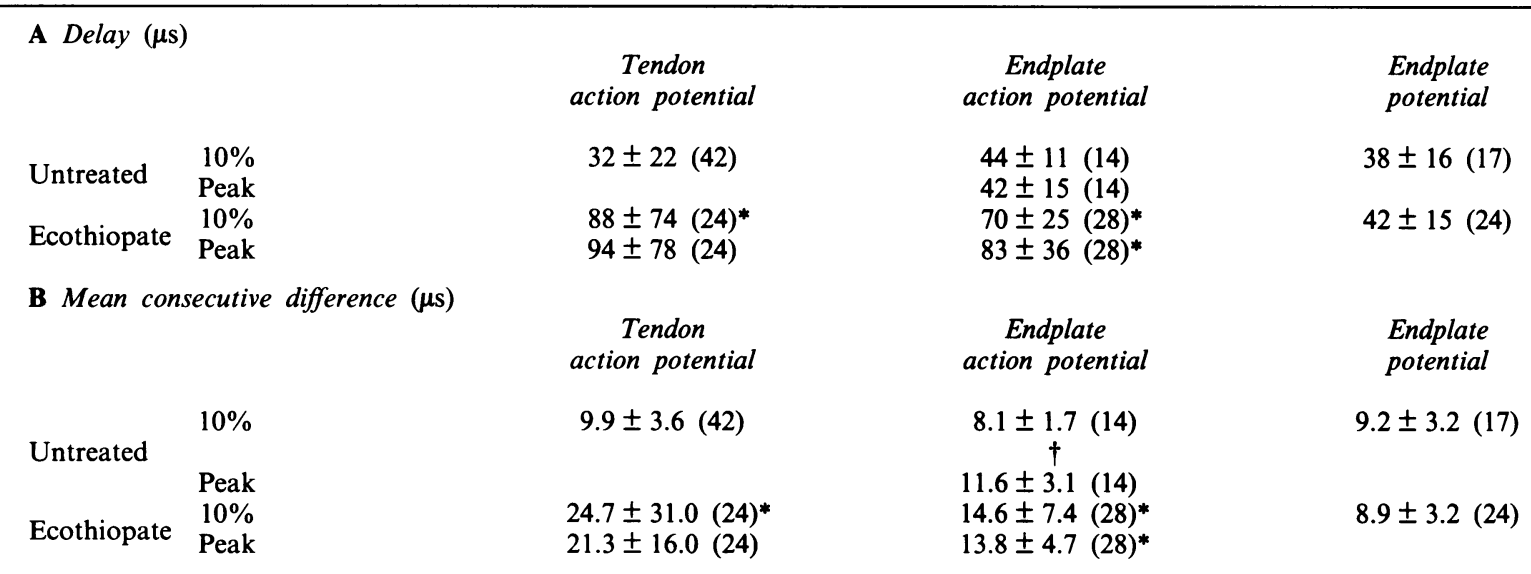

Values are mean \pm 1 s.d. with the number of muscle fibres in parentheses. Asterisk indicates significant difference between values in untreated animals and after ecothiopate $\left(0.5 \mu \mathrm{mol} \mathrm{kg}^{-1}\right)$. †Value at peak different from the value at $10 \%$ trigger level.

Table 4 Neuromuscular transmission in cut fibres 5 days after treatment with ecothiopate $\left(0.5 \mu \mathrm{mol} \mathrm{kg}^{-1}\right)$

\begin{tabular}{|c|c|c|}
\hline Parameter & Untreated & Ecothiopate \\
\hline Resting membrane potential $(\mathrm{mV})$ & $-51 \pm 3(32)$ & $-50 \pm 3(26)$ \\
\hline $\begin{array}{l}\text { Miniature endplate potential } \\
\text { amplitude }(\mathrm{mV})\end{array}$ & $0.53 \pm 0.16(32)$ & $0.49 \pm 0.16(26)$ \\
\hline $\begin{array}{l}\text { Miniature endplate potential } \\
\text { half-decay time (ms) }\end{array}$ & $0.78 \pm 0.19$ & $0.94 \pm 0.38$ \\
\hline $\begin{array}{l}\text { First endplate potential } \\
\text { amplitude }(\mathrm{mV})\end{array}$ & $25.6 \pm 10.1$ & $35.9 \pm 10.8(26)^{*}$ \\
\hline $\begin{array}{l}\text { Plateau endplate potential } \\
\text { amplitude }(\mathrm{mV})\end{array}$ & $17.5 \pm 6.1(32)$ & $20.1 \pm 6.2(26)$ \\
\hline Plateau endplate potential variance & $1.6 \pm 1.3(32)$ & $4.6 \pm 5.4(26)^{*}$ \\
\hline Ratio $\frac{\text { Plateau endplate potential }}{\text { First endplate potential }}$ & $0.70 \pm 0.08$ & $0.56 \pm 0.07(26)^{*}$ \\
\hline Plateau direct $\mathrm{m}$ & $35 \pm 12(32)$ & $43 \pm 15(26)$ \\
\hline Plateau binomial $\mathrm{m}$ & $35 \pm 12(27)$ & $44 \pm 15(24)$ \\
\hline Plateau binomial $\mathrm{n}$ & $41 \pm 15(27)$ & $63 \pm 20(24)^{*}$ \\
\hline Plateau binomial $\mathrm{p}$ & $0.86 \pm 0.08$ & $0.71 \pm 0.15(24)^{*}$ \\
\hline
\end{tabular}

Endplate potentials were elicited at $30 \mathrm{~Hz}$. Values are mean \pm 1 s.d., with the number of muscle fibres sampled in parentheses. Asterisk indicates significant difference between value after ecothiopate and in untreated animals.

preparations the mean consecutive difference, (but not delay) was greater at the peak than at $10 \%$ of peak. At both trigger levels after ecothiopate the delay was greater than in controls, and there was no difference between values at the two trigger levels. Ecothiopate produced an increase in mean consecutive differences measured at $10 \%$ of peak but no significant increase when measured at the peak and after ecothiopate there was no longer a difference between mean consecutive differences at the two trigger levels.

\section{Statistics of transmitter release}

Cutting the muscle fibres to prevent the generation of action potentials also halved the half-decay time of miniature end- 
plate potentials compared with uncut fibres in both untreated and ecothiopate-treated preparations. Five days after treatment with ecothiopate there was no significant change in the half-decay time of miniature endplate potentials in cut fibres. After recording a sample of miniature endplate potentials, the nerve was stimulated at $30 \mathrm{~Hz}$ and the resulting train of endplate potentials was recorded. The amplitude of these endplate potentials ran down to a plateau of $0.5-0.7$ of the first endplate potential. The mean amplitude of plateau endplate potentials after ecothiopate was not different from that in untreated preparations, but the variance of the plateau endplate potentials was significantly greater after ecothiopate treatment. The results of these experiments are summarised in Table 4. After ecothiopate there was an increase in the amplitude of the first endplate potential of trains and of the tetanic run-down i.e. the ratio of plateau endplate potential to first endplate potential. The distribution of the amplitudes of the plateau endplate potentials was binomial in the majority of the fibres from which records were made in untreated mice and after ecothiopate. After ecothiopate, the binomial parameters $n$ and $m$ were increased and the value of $p$ was reduced.

\section{Discussion}

Five days after ecothiopate there was a large increase in jitter of indirectly-evoked action potentials 11 to 30 recorded near the tendon and in the delay of action potential number 16 relative to the first action potential of trains. Ecothiopate had no effect on the jitter or delay of endplate potentials, so altered latency of transmitter release is ruled out as a source of the increased jitter. Other possible causes of increased jitter might be altered conduction along the muscle fibre, altered muscle membrane characteristics or a decreased safety factor of neuromuscular transmission. The observation that in untreated preparations the mean consecutive difference of directly-evoked action potentials was less than that of indirectly-evoked action potentials indicates that much of the jitter can be attributed to the process of neuromuscular transmission.

There was no effect of ecothiopate on the conduction of directly-elicited action potentials along the muscle fibre, even though the action potential had to pass through the endplate region before reaching the recording electrode. Therefore, the increased jitter produced by ecothiopate is not caused by a general effect on the plasma membrane of the muscle fibre and it is concluded that the increased jitter did not originate from some persistent defect in action potential conduction.

Although ecothiopate has no effect on the delay of endplate potentials, it may be that the increased rundown of the endplate potential amplitude at the beginning of trains contributes to the increased delay of action potentials after ecothiopate. This is because smaller endplate potentials would excite nearer their peak than would larger endplate potentials. Furthermore, ecothiopate does have some prejunctional effects which might influence the jitter of indirectlyevoked muscle action potentials. For example, the quantum content of plateau endplate potentials and their calculated binomial parameters were altered by ecothiopate. This effect of ecothiopate on binomial characteristics could not have been due to an acute anticholinesterase effect because adding ecothiopate to cut fibre preparations in vitro had no effect on binomial parameters (Ferry \& Kelly, 1988).

The effectiveness of endplate potentials in exciting action potentials can be assessed by the safety factor for transmission. The safety factor can be expressed as the amplitude of endplate potential divided by the threshold depolarization, both corrected for non-linear summation. In these experiments, the resting membrane potentials, the threshold and the mean amplitude of plateau endplate potentials were not different after ecothiopate. This indicates no change in the mean safety factor. However, in the context of the timing of excitation, it may be the variation in safety factor for individual endplate potentials that is important.

Although the overall mean amplitude of plateau endplate potentials recorded in fibres from animals treated with ecothiopate was not different from that in untreated animals (Table 4), the variance of endplate potential amplitude at the plateau in individual fibres was significantly increased after ecothiopate. Thus after ecothiopate the amplitude of successive plateau endplate potentials in a train had a greater variability, which might contribute to an increased jitter, especially if the bottom end of the range of endplate potential amplitudes were extended. However, close inspection and analysis of the data did not show any increase in the proportion of lower-amplitude endplate potentials after ecothiopate.

In whole (i.e. uncut) muscle fibres, the initial (subthreshold) portion of a potential recorded at the endplate will be the rising phase of the endplate potential which will then give rise to an action potential. Calculating jitter of action potentials at the endplate at $10 \%$ of peak might, therefore, be expected to give similar results to measuring endplate potential jitter, and in control preparations this was found to be true (Table 3). However, the jitter at the peak of the action potential at the endplate is greater than the jitter at $10 \%$ of peak. This indicates that much of the jitter at the peak of action potentials at the endplate in untreated fibres must originate in their excitation. Furthermore, latencies were measured at $10 \%$ of the peak amplitude of the endplate potential, i.e. about $2 \mathrm{mV}$ and near the resting membrane potential. For an action potential at the endplate, the measurement point $(10 \%$ of peak) is about $8-10 \mathrm{mV}$, i.e. on the rising phase of the endplate potential about half way between the resting membrane potential and the threshold depolarization. If the rise-time of the response varied, then the value of the latency would depend upon the point on the response at which the latency is measured. This may be the reason why after ecothiopate, the jitter of action potentials recorded at the endplate is greater than the jitter of endplate potentials.

Jitter measured at the peak of the action potentials recorded at the endplate was not further increased after ecothiopate, despite an increase in mean consecutive difference at $10 \%$ trigger level by some $6 \mu \mathrm{s}$, which suggests that ecothiopate had no effect. However, the rise time of untreated action potentials measured from trigger at $10 \%$ peak to the peak was $234 \pm 37 \mu$ s (20) and although this was not different from after ecothiopate, $244 \pm 35 \mu$ s (29), these values are such that the moderate increase of latency represented by a mean consecutive difference increased by $6 \mu \mathrm{s}$ is likely to be contained in the variance of the rise time after ecothiopate.

The concept of a varying safety factor for transmission, which relates amplitude of endplate potentials and threshold has so far been discussed in terms of varying endplate potentials and constant threshold. However, variation in the threshold for action potential generation would also be expected to result in jitter, as suggested by Stalberg \& Trontelj (1979). Thus the timing of excitation of action potentials would depend on interaction of endplate potentials of variable amplitude with a possibly variable threshold. We have not attempted to measure variations in threshold which might occur over time periods as short as a few milliseconds.

Another possible explanation of the increased jitter of action potentials after ecothiopate is that, due to acetylcholine (ACh) action, there may be variation in the velocity of conduction of action potentials in the locus of excitation. Furthermore, the locus of generation of the action potential may vary between stimuli. The repetitive muscle action potentials after acute intoxication with ecothiopate are generated ectopically from the prolonged endplate potential and after a single stimulus the excitability of the postjunctional membrane is reduced for several tens of milliseconds (Ferry, 1988). To what extent this applies 5 days after ecothiopate and with trains at $30 \mathrm{~Hz}$ is unknown, but repetitive firing was recorded in about $20 \%$ of fibres (Kelly et al., 1990), so this is admissible for consideration. Although the reduction of input 
resistance at the endplate indicates a change there in the length constant of the membrane, this did not affect conduction along the fibre after direct stimulation.

In conclusion increased jitter of indirectly-evoked action potentials after ecothiopate is not caused by either changes in latency or transmitter release or by changes in the conduction of action potentials along the muscle fibre. The increased mean consecutive difference is probably caused by alterations in the process of generation of the action potential at the endplate. This increased variability of excitation at the endplate may be due to an increased variability of time to threshold after ecothiopate and/or it may involve changes in the locus of generation of the action potential. There may also be a postsynaptic component such as variation of threshold for excitation, which may itself depend upon $\mathrm{ACh}$ action. If the threshold were influenced by the immediate history of transmitter action, it may be that with stimulation at $30 \mathrm{~Hz}$, a slight degree of inhibition of functional acetylcholinesterase may become important. Experiments to investigate the possibility that the locus of excitation or the velocity of propagation away from the perijunctional region may change throughout the train may further elucidate the mechanism(s) by which ecothiopate produces increased jitter of indirectly-elicited action potentials.

\section{References}

BAKER, D.J., CROSS, N.L. \& SEDGWICK, E.M. (1987). Normality of single fibre electromyographic jitter: a new approach. J. Neurol. Neurosurg. Psychiatry, 50, 471-475.

BARSTAD, J.A.B. (1962). Presynaptic effect of neuromuscular transmitter. Experientia, 18, 579-581.

EKSTEDT, J., NILSSON, G. \& STALBERG, G. (1974). Calculation of the electromyographic jitter. J. Neurol. Neurosurg. Psychiatry, 37, $526-539$.

FERRY, C.B. (1988). The origin of the anticholinesterase-induced repetitive activity of the phrenic nerve-diaphragm preparation of the rat in vitro. Br. J. Pharmacol., 94, 169-179.

FERRY, C.B. \& KELLY, S.S. (1988). The nature of the presynaptic effects of (+)-tubocurarine at the mouse neuromuscular junction. J. Physiol., 403, 425-437.

HEATH, A.J.W. \& VALE, J.A. (1992). Clinical presentation and diagnosis of acute organophosphate insecticide and carbamate poisoning. In Clinical and Experimental Toxicology of Organophosphates and Carbamates. ed. Ballantyne, B. \& Marrs, T.C. pp. 513-519. Oxford: Butterworth-Heinemann.

HUBBARD, J.I. \& WILSON, D.F. (1973). Neuromuscular transmission in a mammalian preparation in the absence of blocking drugs and the effect of d-tubocurarine. J. Physiol., 228, 307-325.

JOHNSON, M.K. \& VALE, J.A. (1992). Clinical management of acute diagnosis of acute organophosphate poisoning: an overview. In Clinical and Experimental Toxicology of Organophosphates and Carbamates. ed. Ballantyne, B. \& Marrs, T.C. pp. 528-535. Oxford: Butterworth-Heinemann.

KELLY, S.S., FERRY, C.B. \& BAMFORTH, J.P. (1990). The effects of anticholinesterases on the latencies of action potentials in mouse skeletal muscles. Br. J. Pharmacol., 99, 721-726.

KELLY, S.S., FERRY, C.B., BAMFORTH, J.P. \& DAS, S.K. (1992) Protection against the effects of anticholinesterases on the latencies of action potentials in mouse skeletal muscles. Br. J. Pharmacol., 107, 867-872.

KELLY, S.S. \& ROBBINS, N. (1987). Statistics in neuromuscular transmitter release in young and old mouse muscle. J. Physiol., 385, 507-516.

MCLACHLAN, E. (1978). The statistics of transmitter release at chemical synapses. Int. Rev. Physiol., 17, 49-117.

MCLACHLAN, E.M. \& MARTIN, A.R. (1981). Non-linear summation of end-plate potentials in the frog and mouse. J. Physiol., 311 307-324.

MARTIN, A.R. (1955). A further study of the statistical composition of the endplate potential. J. Physiol., 130, 114-122.

MIYAMOTO, M.D. (1975). Binomial analysis of quantal transmitter release at glycerol treated frog neuromuscular junctions. J. Physiol., 250, 121-142.

STALBERG, E. \& TRONTELJ, J.V. (1979). Single Fibre Electromyography. Old Woking, Surrey: The Miravelle Press.

(Received July 20, 1993

Revised November 1, 1993

Accepted November 12, 1993 